\title{
OPTIMALISASI RUANG PENYIMPANAN GUDANG BARANG JADI PT XYZ DENGAN PENERAPAN RACKING SYSTEM UNTUK MENINGKATKAN KAPASITAS GUDANG MENGGUNAKAN ALGORITMA DYNAMIC PROGRAMMING
}

\author{
${ }^{1}$ Muhammad Riski, ${ }^{2}$ Ari Yanuar, ${ }^{3}$ Budi Santosa \\ 1,2,3 Program Studi Teknik Industri, Fakultas Rekayasa Industri, Telkom University \\ 1'muhriski@student.telkomuniversity.ac.id, ${ }^{2}$ ariyanuar@telkomuniversity.ac.id, ${ }^{3}$ bschulasoh@gmail.com
}

\begin{abstract}
Abstrak - PT XYZ merupakan sebuah perusahaan yang bergerak dalam bidang industri elektronika dan prasarana. PT XYZ memiliki sebuah gudang barang jadi yang menyimpan produk solar modul. Gudang mengalami overcapacity yang menyebabkan tidak mampunya menampung barang yang akan masuk karena penuhnya ruang penyimpanan. Hal tersebut disebabkan oleh sistem penyimpanan di gudang masih menggunakan floor stake dengan satu level dan media penyimpanan palet yang berukuran $1.7 \mathrm{~m} \times 1.1 \mathrm{~m}$ yang memiliki batas maksimum penumpukan 10 tumpukan karton. Sementara itu, tinggi gudang yang digunakan saat ini hanya $1.19 \mathrm{~m}$ padahal tinggi bersih gudang yang dapat digunakan adalah $6 \mathrm{~m}$. Hal tersebut membuat utilisasi gudang saat ini secara volumetric sangat rendah yaitu sebesar $18 \%$. Tujuan dari penelitian ini adalah untuk meningkatkan kapasitas dan utilisasi gudang barang jadi PT XYZ. Permasalahan diselesaikan dengan menggunakan algoritma dynamic programming dengan cara mengkombinasikan antara rak selective dan non-selective (drive-in) untuk memaksimalkan jumlah lane untuk masing-masing rak untuk dapat memenuhi kebutuhan storage area pada gudang. Hasil dari penelitan ini adalah meningkatnya kapasitas gudang PT XYZ dari kondisi saat ini yang memiliki kapasitas 156 palet posisi meningkat menjadi 492 palet posisi pada kondisi usulan.
\end{abstract}

Kata kunci: Floor stake, kapasitas gudang, algoritma dynamic programming, jumlah lane, volumetric, overcapacity

\section{PENDAHULUAN}

Sistem penyimpanan barang di gudang PT XYZ adalah dengan sistem floor stake dengan satu level menggunakan palet yang berukuran $1.7 \mathrm{~m} \mathrm{x} 1.1 \mathrm{~m}$ dengan tinggi $14 \mathrm{~cm}$. Berdasarkan kebijakan perusahaan maksimal penumpukan dalam palet adalah 10 tumpukan. Indikasi terjadinya overcapacity di gudang disebabkan oleh kapasitas gudang yang tidak mampu memenuhi inventory yang ada dalam gudang. Gambar 1 menunjukkan perbandingan antara kapasitas gudang dengan jumlah inventory di gudang setiap bulan dalam satuan palet.
Pada Gambar 1 terdapat kelebihan kapasitas pada bulan Mei, Juni, Juli, Agustus dan Oktober tahun 2016. Kelebihan barang yang tidak dapat ditampung dalam gudang tersebut kemudian ditempatkan untuk sementara di gedung produksi. Sementara itu, karena pergerakan barang yang lambat menyebabkan terjadinya penumpukan barang di gudang.

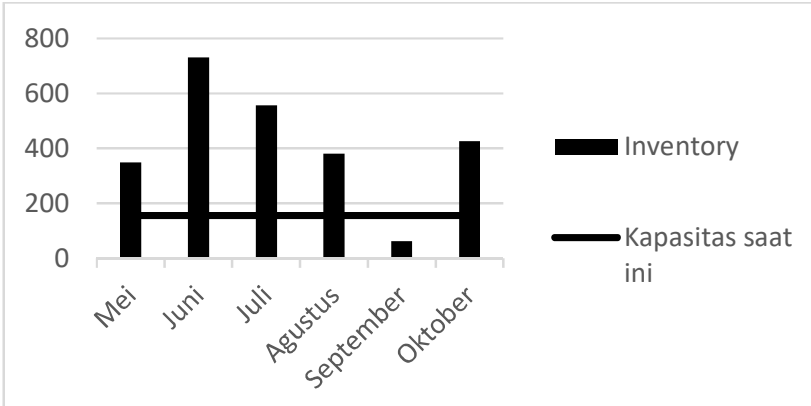

Gambar 1 Perbandingan antara inventory dan kapasitas gudang dari bulan Mei sampai Oktober tahun 2016

Pergerakan barang sangat mempengaruhi jumlah inventory di gudang. Gambar 2 menunjukkan inventory turnover pada gudang dalam setiap bulannya. Jumlah tersebut masih relatif kecil karena menurut [1] nilai inventory turnover yang ideal untuk sebuah perusahaan manufaktur adalah dalam kisaran 1020 setiap bulan.

Selain itu, persentase utilisasi gudang dalam volumetric adalah sebesar $18 \%$, yang terdiri dari $7 \%$ untuk staging area dan $11 \%$ untuk area penyimpanan floor stake untuk setiap produk karena menurut [2] untuk merancang kebutuhan ruang untuk setiap produk harus dihitung berdasarkan jumlah maksimum barang yang ada di gudang. Namun, nilai tersebut masih relatif kecil karena menurut [3] maksimal penyimpanan di gudang adalah $80 \%$ sedangkan sisanya digunakan untuk aisle dan keperluan lain-lain. Penyebab rendahnya nilai utilisasi gudang disebabkan oleh sistem penyimpanan floor stake yang 
mamakan banyak ruang secara horizontal sementara secara vertikal hanya menggunakan $1.19 \mathrm{~m}$ dari total tinggi gudang yang dapat digunakan setinggi $6 \mathrm{~m}$.

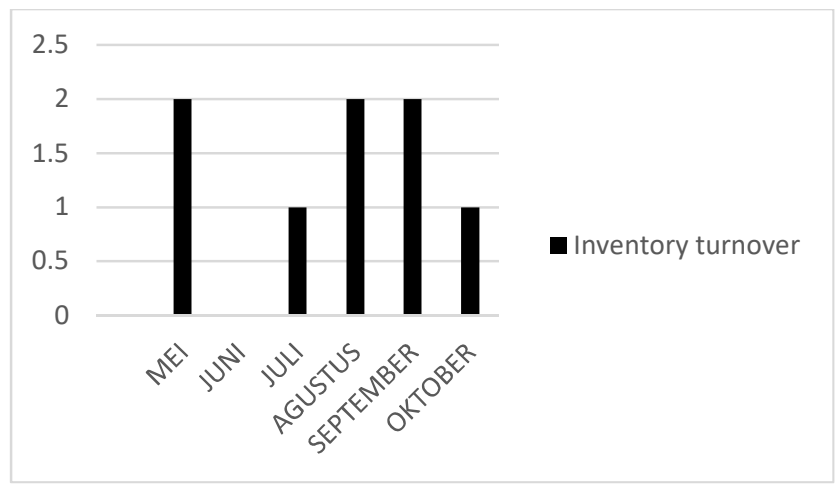

Gambar 2 Data inventory turnover dari bulan Mei sampai Oktober 2016

\section{STUDI LITERATUR}

Suply Chain secara umum merupakan sebuah jaringan yang menghubungkan beberapa fasilitas dari hulu yang merupakan pembelian barang mentah hingga diubah menjadi barang jadi. Termasuk didalamnya aktivitas distribusi dan penjulan barang jadi hingga ke tangan customer [4].

\section{A. Gudang}

Gudang adalah fasilitas untuk yang bertujuan untuk menyimpan barang sebagai penyangga permintaan sehingga permintaan yang terjadi dapat dipenuhi. Selain itu, gudang juga berfungsi menjadi titik pengiriman barang dimana semua barang diterima dan dikirim secepat, seefektif dan seefisien mungkin [5]. Berikut ini adalah jenisjenis gudang menurut [6]:

1. Gudang raw material dan komponen: Sebagai tempat menyimpan raw material ataupun komponen-komponen yang digunakan untuk produksi.

2. Gudang work in process : Sebagai tempat penyimpanan barang work in process.

3. Gudang barang jadi : Sebagai tempat penyimpanan barang jadi.

4. Distribution center : Sebagai tempat menyimpan barang sebelum dikirim ke costumer.

5. Fulfillment center : Sebagai tempat yang menerima dan mengirim pesanan dalam jumlah kecil langsung ke end costumer.

6. Gudang lokal : Sebagai tempat menyimpan dan mengirim barang namun dalam cakupan area yang kecil.

\section{B. Pallet Storage}

Peralatan penyimpanan (storage equipment) digunakan untuk penyangga dari produk jadi selama periode waktu tertentu. Pallet Storage merupakan sistem penyimpanan yang dilakukan dengan menggunakan pallet. Pallet merupakan salah satu alat yang dibutuhkan untuk menumpuk dari produk. Berikut ini adalah pallet storage system yang sering digunakan pada pergudangan [6], yaitu:

\section{Block stacking}

Block stacking merupakan penumpukan yang ditempatkan di atas lantai. Penumpukan biasanya terdiri dari dua blok atau penumpukkan berdasarakan batas aman penumpukkan yang sesuai dengan kebijakan.

2. Stacking frames

Stacking frames merupakan alternatif dari penggunaan rak dalam bentuk stacking frame yang memiliki pallet pada alasnya dan juga terdapat penyangga yang memudahkan dalm proses penumpukannya.

3. Rak Singgle-deep selective pallet

Rak paling sering digunakan di gudang, karena rak tersebut memiliki kelebihan yaitu akses yang lebih mudah dan cepat dibanding lainnya. Rak ini memiliki sistem penyimpanan FIFO (First In First Out) sehingga pengguanaan rak ini akan sangat mengungkan karena waktu yang dikeluarkan tidak akan terlalu lama. Namun, rak jenis ini memakan banyak tempat sehingga membuat utilisasi gudang kecil.

4. Rak Double-deep

Rak drive-in merupakan media penyimpanan yang memiliki rak ganda, sehingga penyimpanan menjadi lebih besasr. Rak ini memiliki sistem penyimpanan LIFO (Last In First Out). Cenderung memiliki kapasitas yang besasr, namun hanya dapat diakses melalui satu sisi.

5. Rak Drive-thru

Rak yang berjenis FIFO yang cenderung memiliki kapasitas yang lebih besar. Cara kerja dari rak ini adalah dengan menyimpan palet pada rak yang dibantu dengan menggunakan alat material handling berupa forklift. Rak jenis memiliki dua akses yaitu dari depan dan belakang. Namun, rak jenis ini membutuhkan operator yang handal karena dalam menggunakan forklift.

C. Tata letak

Tata letak gudang adalah penempatan suatu lokasi yang ditentukan berdasarkan fungsi dari lokasi tersebut agar fungsi dari gudang dapat berjalan secara efektif. Menurut [6] menentukan tata letak yang sesuai untuk gudang harus mengikuti 5 tahapan, yaitu:

1. Menentukan keseluruhan ruang yang dibutuhkan dalam proses pergudangan

2. Menentukan flow material

3. Menentukan lokasi setiap fungsi gudang berdasarkan kedekatan satu sama lain

4. Menentukan penyimpanan dengan permintaan yang besar berada pada lokasi yang mudah dijangkau sendangkan penyimpanan dengan permintaan rendah beradapa pada lokasi sebaliknya.

5. Melakukan perluasan proses gudang.

Selain itu, menurut [7] beberapa hal dasar yang perlu diperhatikan dalam perancangan gudang diantaranya:

1. Pemahaman industri yang akan dijalankan.

2. Komoditi barang yang dikelola.

3. Luas gudang yang ada.

4. Jenis aktifitas yang dilakukan di gudang.

5. Fasilitas non operasional yang harus ada. 


\section{Algoritma dynamic programming}

Metode penelitan yang digunakan dalam penelitian ini mengadopsi hasil dari Penelitan yang dipublikasikan oleh [8] pada acara konferensi di Montreal, Canada menghasilkan sebuah prosedur/algoritma pemecahan masalah yang memiliki memaksimalkan jumlah kapasitas penyimpanan gudang dengan mengkombinasikan antara dua alternatif rak yaitu rak jenis selective dan rak jenis non-selective (yang memiliki akses LIFO). Secara khusus, rak yang di analisis memungkinkan untuk memiliki tinggi yang berbeda untuk masing-masing level. Selain itu, utilisasi volumetric dan efisiensi penyimpanan gudang akan menjadi key performance indicator, yang akan diselesaikan dengan mengkombinasikan antara kedua alternatif rak tersebut untuk mencapai hasil yang optimal. Dalam penerapannya permasalahan diselesaikan dengan menggunakan mathematical programming untuk mendapatkan hasil-hasil yang disebutkan diatas. Hasil akhir dari algoritma tersebut adalah peneliti dapat mengetahui jumlah kombinasi optimal antara rak selective dan rak non-selective berikut dengan lane depth sehingga penyimpanan secara volumetric menjadi maksimal. Berikut ini adalah prosedur pembentukan model matematika hasil penelitan [8] yang digunakan pada penelitian ini:

1. Menghitung interval pengosongan untuk item $j$ yang pada rak non-selective

$$
I_{j t r}=\frac{z_{t}^{d} r}{d_{j}}
$$

2. Jumlah interval pengosongan dapat dihitung dengan menggunakan cycle time sebagai berikut :

$$
K_{j t r}=\left[\frac{T_{C_{j}}}{I_{j t r}}\right]
$$

3. Kemudian, untuk setiap interval pengosongan $k$, dengan nilai $k=1, \ldots, \mathrm{K}_{\mathrm{jtr}}$, memiliki jumlah lanes yang dibutuhkan berupa $N_{j t r}(k)$ yang tergantung kepada nilai maksimal inventory level dalam interval pengosongan dengan notasi yang dinyatakan dengan $i_{j t r}^{M}(k)$ dengan syarat sebagai berikut :

$$
i_{j t r}^{M}(k)=
$$

$$
\left\{\begin{array}{cr}
\left\{\begin{array}{cr}
s_{j}+\left(p_{j}-d_{j}\right) I_{j t r} & \text { jika } k=1, \\
i_{j t r}^{M}(k-1)+\left(p_{j}-d_{j}\right) I_{j t r} & \text { jika } k I_{j t r}<T_{p_{j}}
\end{array}\right. \\
\left\{\begin{array}{lr}
I_{j}^{M} & j i k a(k-1) I_{j t r}<T_{p_{j}} \leq k I_{j t r} \\
I_{j}^{M}-\left((k-1) I_{j t r}-T_{p_{j}}\right) d_{j} & \text { jika }(k-1) I_{j t r} \geq T_{p_{j}}
\end{array}\right.
\end{array}\right.
$$

4. Sehingga jumlah lane untuk rak tipe $t$ dan kedalaman $\mathrm{r}$ pallet sekian untuk item $j$ dalam interval pengosongan $k$ (dengan nilai $k=1, \ldots, K_{j t r}$ ) dapat ditentukan dengan rumus

$$
N_{j t r}(k)=\left\lceil\frac{i_{j t r}^{M}(k)}{r z_{t}^{d}}\right\rceil
$$

5. Lalu, untuk menghitung jumlah rata-rata lane untuk masingmasing tipe penyimpanan item $j$ dapat diekspresikan dengan:

$$
\bar{N}_{j t r}=\frac{I_{j t r} \Sigma_{k=1}^{K_{j t r-1}} N_{j t r}(k)+\left(T_{C_{j}}-\left(K_{j t r}-1\right) I_{j t r}\right) N_{j t r}\left(K_{j t r}\right)}{T_{C_{j}}}
$$

Catatan: jika waktu siklus bukan bilangan bulat kelipatan interval pengosongan, sehingga interval pengosongan terakhir harus menggunakan rumus $\left(T_{C_{j}}-\left(K_{j t r}-1\right) I_{j t r}\right)$.

6. Akhirnya, setiap item $j$ yang disimpan dalam lane pada tipe dan kedalaman r-pallet tertentu dapat diketahui efisiensi penyimpanannya adalah rasio antara jumlah lokasi pallet yang terisi dengan jumlah lokasi pallet yang disediakan untuk item dalam selang waktu siklus, dengan cara :

$e_{j t r}=\frac{2 T_{C} s_{j}+T_{C_{j}}\left(I_{j}^{M}-s_{j}\right)}{2 z_{j t} r\left(I_{j t r} \sum_{k=1}^{K}{ }_{j t r}^{-1} N_{j t r}(k)+\left(T_{C_{j}}-\left(K_{j t r}-1\right) I_{j t r}\right) N_{j t r}\left(K_{j t r}\right)\right)}(6)$

7. Selanjutnya adalah menghitung utilisasi masing-masing alternativf. Untuk alternative rak selective menggunakan rumus sebagai berikut :

$$
u^{s}=\frac{w d}{\left(D^{s}+A^{s} / 2\right) W^{s}}
$$

Sedangkan untuk non-selective racks dengan kedalaman $r$-pallet tertentu memiliki rumus sebagai berikut:

$$
u^{d}=\frac{r w d}{\left(r D^{d}+A^{d} / 2\right) w^{d}}
$$

8. Selanjutnya adalah menghitung level ambang atas dengan mempertimbangkan masing-masing untilitas antara kedua alternatif tersebut. Jumlah level untuk rak selective ditnotasikan sebagai $\mathrm{z}^{\mathrm{s}}$, sedangkan untuk rak non-selective dinotasikan sebagai $z_{t}^{d}$. Maka, rumus yang digunakan adalah sebagai berikut :

$$
e_{t r}^{T}=\frac{u^{s} z^{s}}{u^{d} z_{t}^{d}}
$$

Jika nilai dari $e_{j t r}<e_{t r}^{T}$ maka item tersebut akan menggunakan rak selective. Sedangkan, apabila $e_{j t r}>e_{t r}^{T}$ maka terdapat dua alternatif antara selective dan nonselective.

9. Selanjutnya, keputusan untuk menentukan alternatif yang terpilih adalah menggunakan integer programming 0-1 dengan syarat sebagai berikut :

$$
\begin{aligned}
& x_{j t r}=\left\{\begin{array}{l}
1 \text { jika yang terpilih adalah alternatif non }- \text { selective } \\
0 \text { sebaliknya }
\end{array} \forall j, t, r\right. \\
& y_{j}=\left\{\begin{array}{c}
1 \text { jika yang terpilih adalah alternatif selective } \\
0 \text { sebaliknya }
\end{array} \forall j\right.
\end{aligned}
$$


10. Fungsi tujuan untuk penentuan pilihan tersebut adalah menggunakan fungsi maksimasi yang merupakan jumlah palet volumetric masing-masing item dalam gudang sebagai berikut :

$\operatorname{Max} f\left(x_{j t r}, y_{j}\right)=\sum_{j} \sum_{t} \sum_{r} \frac{r w d h_{j}}{\left(r D^{d}+A^{d} / 2\right) W^{d} H_{t}^{d}} e_{j t r} x_{j t r}+\sum_{j} \frac{d w h_{j}}{\left(D^{s}+A^{s} / 2\right) w^{\supset} H^{\circ}}$

Perlu diperhatikan bahwa fungsi tujuan $f\left(x_{j t r}, y_{j}\right)$ secara jelas bergantung terhadap efisiensi penyimpanan $e_{j t r}$ untuk $x_{j t r}$ (non-selective) dan sama dengan 1 untuk $y_{j}$ (selective).

11. Pembatas-pembatas yang digunakan untuk fungsi tujuan :

Pembatas (13) untuk menjaminan bahwa apabila item $j$ ditempatkan pada non-selective racks dan ditempatkan sesuai tipe dan kedalaman :

$$
\sum_{t} \sum_{r} x_{j t r} \leq 1, \quad \forall_{j}
$$

Pembatas (14) untuk memastikan bahwa apabila item $j$ ditempatkan pada rak selective rack.

$$
y_{j}=1-\sum_{t} \sum_{r} x_{j t r}, \forall_{j}
$$

Pembatas (15) untuk menjaminan bahwa bahwa luas area yang dibutuhkan untuk sistem penyimpanan tidak melebihi luas area penyimpanan yang tersedia pada gudang. Sebagai berikut :

$$
\sum_{j} \sum_{t} \sum_{r}\left(r D^{d}+\frac{A^{d}}{2}\right) W^{d} \bar{N}_{j t r} x_{j t r}+\sum_{j}\left(D^{s}+\frac{A^{s}}{2}\right) W^{s} \frac{\bar{I}_{j}}{z^{s}} y_{j} \leq .
$$

Pembatas (16) untuk mencegah setiap item untuk ditempatkan pada lane non-selective racks jika interval pengosongan melebihi periode maksimal dari waktu penyimpanannya. Sebagai berikut :

$$
x_{j t r} \frac{I_{j t r}}{I_{j}^{\text {max }}} \leq 1, \quad \forall_{j, t, r}
$$

Pembatas (17) untuk mencegah item ditempatkan pada nonselective racks ketika selective racks lebih cocok untuk item tersebut yang mendefinisikan efisiensi penyimpanan dan tingkat ambang batasnya. Sebagai berikut :

$$
x_{j t r} \leq 1+\frac{e_{j t r}-e_{r}^{T}}{e_{r}^{T}}, \forall_{j, t, r}
$$

Pembatas (18) memastikan bahwa variabel keputusan adalah bilangan bulat dan bernilai nol-satu (binary).

$$
x_{j t r}, y_{j} \in\{0,1\}, \forall_{j, t, r}
$$

Keterangan :

$j=1, \ldots, J$ : SKUs atau produk yang akan disimpan pada gudang;

$t=1, \ldots, T$ : jenis dari non-selective racks; $r=1, \ldots, R$ : kedalaman rak (satuan jumlah pallet posisi) dari non-selective racks.

$w, d$ : panjang dan lebar (dalam meter) dari tumpukan produk/unit loads;

$W^{d}, D^{d}$ : panjang dan lebar (meter) untuk satu pallet posisi dari non-selective racks (termasuk allowance yang diperlukan antara unit laods dengan rangka rak);

$W^{s}, D^{s}$ : panjang dan lebar (dalam meter) untuk satu pallet posisi dari selective racks (termasuk allowance yang diperlukan antara unit loads dengan rangka rak);

$h_{j}$ : ketinggian (dalam meter) tumpukan untuk produk $j$;

$H_{t}^{d}$ : ketinggian (dalam meter) satu level lanes untuk rak nonselective racks;

$H^{s}$ : ketinggian (dalam meter) satu level lanes untuk rak selective racks;

$z_{t}^{d}$ : jumlah level lanes untuk non-selective racks.

$z^{s}$ : jumlah level lanes untuk selective racks.

$A^{d}$ : lebar (dalam meter) lorong untuk non-selective racks.

$A^{s}$ : lebar (dalam meter) lorong untuk selective racks.

$S^{\text {tot }}$ : luas area penyimpanan yang tersedia pada gudang.

$p_{j}, r_{j}$ : tingkat produksi dan tingkat permintaan, untuk produk $j$ (dalam satuan unit loads per hari)

$T c_{j}, T p_{j}$ : waktu siklus dan waktu prodksi (dalam hari) untuk produk $j$.

$s_{j}:$ safety stock

$I_{j}^{M}, \bar{I}_{j}$ : tingkat persediaan maksimum dan rata-rata (dalam satuan unit loads). Maka, $I_{j}^{M}=s_{j}+\left(p_{j}-r_{j} T_{p j}\right.$ dan $\bar{I}_{j}=$ $s_{j}+I_{j}^{M} / 2$

$I_{j}^{\max }$ : periode penyimpanan maksimal dari produk $j$ (dalam hari)

$e_{j t r}$ : efisiensi penyimpanan dari produk $j$ apabila produk disimpan pada non-selective racks dengan kedalaman r-pallet deep.

$e_{t r}^{T}$ : tingkat ambang batas untuk efisiensi penyimpanan pada non-selective racks.

$\bar{N}_{j t r}$ : rata-rata jumlah lanes dengan kedalaman r-pallet deep yang dibutuhkan untuk menyimpan produk $j$.

\section{METODOLOGI PENELITIAN}

Sistematika pemecahan masalah bertujuan untuk menjelaskan secara sistematis proses-proses yang dilakukan dalam pemecahan masalah. Gambar 3 mendeskripsikan tentang sistematika pemecahan masalah dalam penelitian. Terdapat 3 tahap yang dilakukan dalam penelitian ini, yaitu tahap pengumpulan dan pengolahan data, tahap analisis dan tahap kesimpulan dan saran.

A. Tahap pengumpulan dan pengolahan data

Pada tahap ini adalah melakukan pengumpulan data mentah terkait yang akan digunakan untuk menyelesaikan permasalahan terjadi pada gudang. Data tersebut terdiri dari data primer yaitu data yang diambil langsung oleh peneliti dengan cara melakukan observasi langsung ke lapangan dan data sekunder merupakan data yang historis yang telah didokumentasikan/dibukukan oleh perusahaan. 
Kemudian, setelah mendapatkan data-data yang dibutuhkan selanjutnya adalah menghitung jumlah inventory untuk masing-masing bulan di gudang berdasarkan data yang telah didapat. Selanjutnya, adalah menghitung nilai throughput selama periode penelitian. Setelah itu adalah menghitung utilisasi gudang saat ini. Setelah mengetahui jumlah inventory, throughput dan utilisasi maka selanjutnya adalah merancang

rak yang disesuaikan dimensi palet dan gudang pada kondisi saat ini. Perancangan meliputi penentuan ketinggian palet dengan maksimum tumpukan, ketinggian setiap level rak, panjang bay, kedalaman rak, jumlah level, dll. Setelah merancang rak yang sesuai dengan kondisi saat ini, maka selanjutnya adalah menentukan material handling equipment yang akan digunakan sebagai usulan. Setelah itu, menghitung lebar minimal aisle, menurut [9] layout dan dimensi material handling adalah hal yang menentukan lebar minimum aisle dan pencarian alternatif jalur aisle dengan mempertimbangkan material handling equipment yang digunakan.

Selanjutnya adalah menghitung kombinasi optimal untuk mencapai kapasitas maksimum menggunakan algoritma dynamic programming. Data yang dibutuhkan untuk menggunakan algoritma tersebut adalah production rate, demand rate, production time, cycle time, safety stock dan dimensi rak. Kemudian, pada perhitungan fungsi tujuan menggunakan integer linier programming 0-1 disimulasikan menggunakan software lingo untuk menghasilkan nilai optimum. Setelah mengetahui jumlah kombinasi yang sesuai untuk permasalahan maka selanjutnya adalah merancang layout usulan dengan mempertimbangkan aisle dan picking area untuk memungkinkan aktivitas pengambilan dan peletakan barang. Kondisi layout gudang yang paling baik harus memenuhi karakteristik modularitas yang baik, kemampuan beradaptasi, keselarasan, distribusi gerakan yang efektif, mudah diakses dan fleksibel. [10]

\section{B. Tahap analisis}

Pada tahap analisis akan ditunjukkan gap yang berhasil ditingkatkan dari kondisi saat ini. Parameter yang digunakan disesuaikan dengan tujuan penelitian yaitu untuk meningkatkan kapasitas. Sehingga, akan ditunjukkan gap yang terjadi antara kapasitas gudang saat ini dengan usulan. Setelah itu, dilakukan analisis validasi.

\section{Tahap kesimpulan dan saran}

Pada tahap ini akan dirangkum hasil-hasil dari pengumpulan data, pengolahan data dan analisis yang dilakukan penelitian ini beserta saran.

\section{HASIL DAN ANALISIS}

A. Hasil

Berdasarkan algoritma [8] maka dilakukan perhitungan jumlah lane optimal yang sesuai dengan permasalahan yang terjadi dengan menggunakan input berupa ukuran dimensi rak dan data production rate, demand rate, production time, cycle time dan safety stock yang ditampilkan pada Tabel I dan Tabel II. Data pada Tabel I merupakan data yang didapatkan berdasarkan perancangan yang telah dilakukan menyesuaikan dengan teori-teori yang digunakan. Sedangkan, data pada Tabel II meruapakan data primer dan data sekunder yang didapatkan berdasarkan observasi dan berdasarkan data historis dari perusahaan.

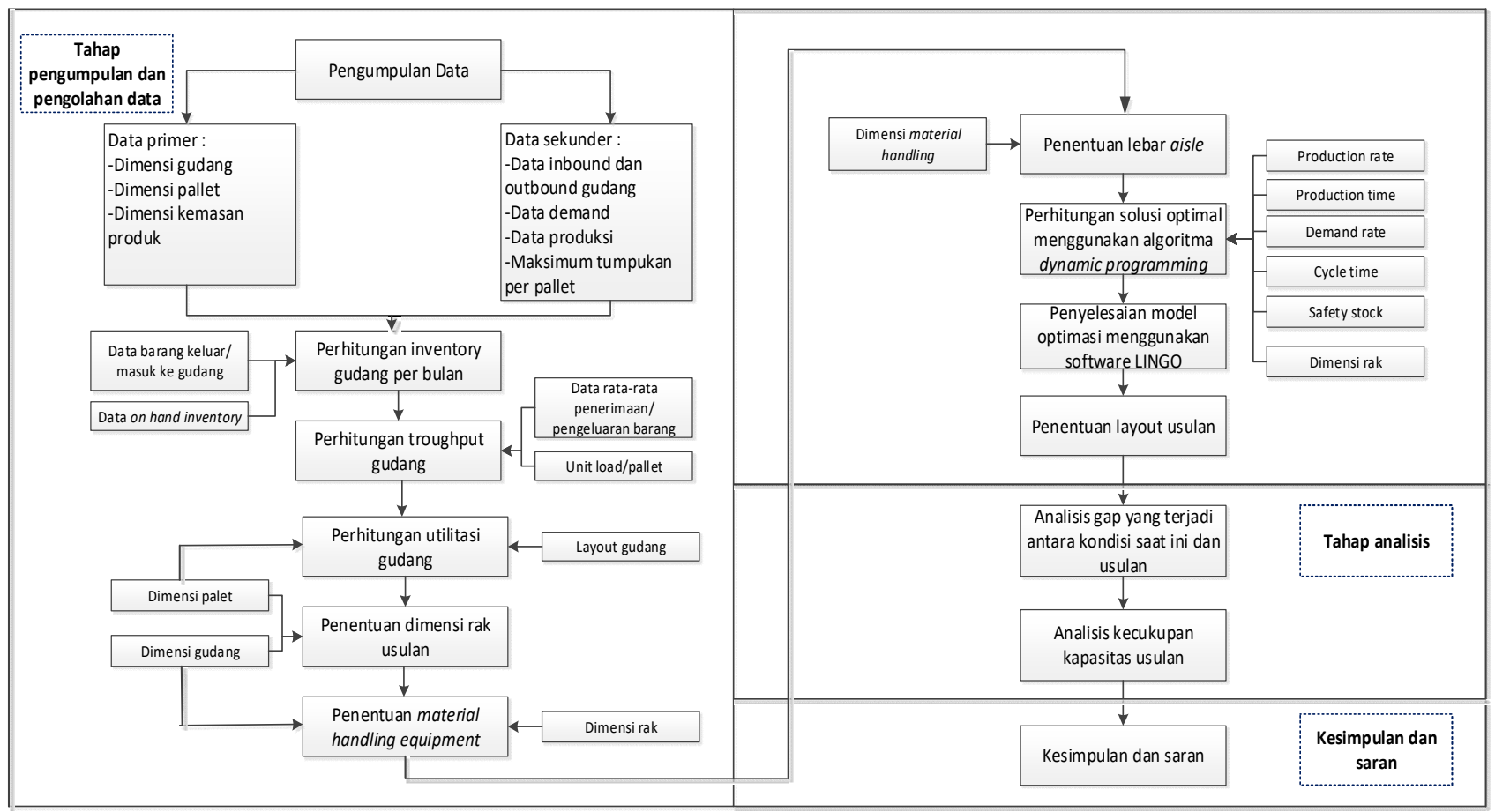

Gambar 3 Sistematika pemecahan masalah 
TABEL I

DIMENSI RAK

\begin{tabular}{|c|c|c|}
\hline & $\begin{array}{c}\text { Rak } \\
\text { SELECTIVE }\end{array}$ & $\begin{array}{c}\text { Rak } \\
\text { DRIVE-IN }\end{array}$ \\
\hline $\boldsymbol{D}^{\boldsymbol{S}}$ (Meter & 1.9 & 1.9 \\
\hline $\boldsymbol{W}^{\boldsymbol{S}}$ (Meter) & 1.33 & 1.41 \\
\hline $\boldsymbol{H}^{\boldsymbol{S}}$ (Meter) & 5.66 & 5.66 \\
\hline $\mathbf{Z}^{\boldsymbol{S}}$ & 4 & 4 \\
\hline
\end{tabular}

TABEL II

DATA INPUT ALGORITMA

\begin{tabular}{|l|c|c|c|c|c|}
\hline & $\begin{array}{c}\text { Production } \\
\text { rate (unit } \\
\text { loads) }\end{array}$ & $\begin{array}{c}\text { Demand } \\
\text { rate } \\
\text { (unit } \\
\text { loads) }\end{array}$ & $\begin{array}{c}\text { Production } \\
\text { time (hari) }\end{array}$ & $\begin{array}{c}\text { Cycle } \\
\text { time } \\
\text { (hari) }\end{array}$ & $\begin{array}{c}\text { safety } \\
\text { stock } \\
\text { (unit } \\
\text { loads) }\end{array}$ \\
\hline $\begin{array}{l}\mathbf{1 0 0} \mathbf{~ W p} \\
\mathbf{1 2} \mathbf{~ V}\end{array}$ & 9 & 7 & 12 & 15 & 5 \\
\hline $\mathbf{2 0 0} \mathbf{~ W p}$ & 8 & 6 & 13 & 17 & 5 \\
\hline $\mathbf{2 6 0} \mathbf{~ W p}$ & 287 & 254 & 13 & 17 & 104 \\
\hline
\end{tabular}

Hasil yang didapatkan berdasarkan perhitungan menggunakan algoritma yang diguanakan ditampilkan pada Tabel III. Jumlah lane optimal yang didapatkan adalah 43 lane untuk rak drive-in dengan kedalaman 3 sedangkan 6 lane untuk rak selective. Dalam setiap lane rak drive-in dengan kedalaman 3 memiliki 12 slot palet sedangkan rak selective memiliki 4 slot palet untuk masing-masing lane. Total slot untuk masingmasing rak adalah 468 slot palet untuk rak drive-in dan 24 palet untuk rak selective. Sehingga total keseluruhan slot untuk masing-masing rak adalah 492 slot palet.

TABEL III

\begin{tabular}{|c|c|c|}
\hline Tipe rak & Depth ( r ) & Jumlah \\
\hline \multirow{4}{*}{ DRIVE-IN } & 3 & 43 \\
\hline & 4 & 0 \\
\hline & 5 & 0 \\
\hline & 6 & 0 \\
\hline SELECTIVE & & 6 \\
\hline \multicolumn{2}{|c|}{ TOTAL } & 49 \\
\hline
\end{tabular}

B. Analisis

Perbandingan kondisi layout gudang saat ini dengan usulan ditampilkan pada lampiran. Pada layout gudang saat ini dengan sistem penyimpanan menggunakan floor stake satu level. Sedangkan, layout usulan menggunakan racking system dengan kombinasi antara rak drive-in dan rak selective dan menggunakan dimensi vertikal hingga 4 level dengan ketinggian $5.58 \mathrm{~m}$.

Selain itu, perbandingan kapasitas antara gudang kondisi saat ini dan usulan meningkat sebesar 32\%. Pada kondisi saat ini kapasitas gudang hanya dapat menampung sebanayak 156 slot palet sementara pada kondisi kapasitas usulan gudang dapat menampung sebanyak 492 slot palet. Sebagaimana ditampilkan pada Tabel IV.
TABEL IV

PERBANDINGAN KAPASITAS SAAT INI DENGAN USULAN
\begin{tabular}{|l|c|c|}
\hline Kondisi & $\begin{array}{c}\text { Kapasitas } \\
\text { (palet posisi) }\end{array}$ & $\begin{array}{c}\text { Peningkatan } \\
\mathbf{( \% )}\end{array}$ \\
\hline Saat ini & 156 & $32 \%$ \\
\hline Usulan & 492 & \\
\hline
\end{tabular}

Menurut [6] jika perbandingan antara level maksimum inventory dengan rata-rata level inventory memiliki rasio lebih besar daripada 1.5 maka gudang dapat melakukan temporary space (menyewa gudang/trailer sorage) sebagai solusi pemecahan masalah. Sedangkan, apabila rasio antara maksimum inventory dengan rata-rata level inventory adalah kurang dari 1.2 maka gudang tidak membutuhkan temporary space. Kondisi inventory saat ini adalah memeiliki nilai puncak pada bulan Juni yaitu sebesar 732 palet posisi dan rata-rata inventory setiap bulan adalah 418, seperti pada Gambar 4.

Perbandingan rasio antara titik puncak dan rata-rata adalah 732 : 418 yaitu sebesar 1.7, sehingga berdasarkan teori tersebut maka berdasarkan [6] perbandingan sudah melebihi rasio 1.5. Maka, perbandingan tersebut akan dijadikan parameter pengukuran untuk menentukan jumlah inventory sebagai batas atas dan bawah untuk dibandingkan dengan hasil optimal dari kapasitas yang sudah dihitung.

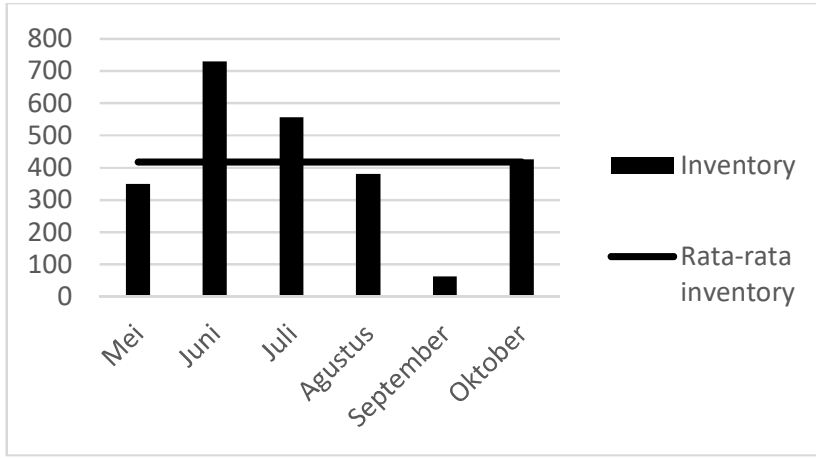

Gambar 4 Perbandingan rata-rata inventory dengan kapasitas gudang usulan

Karena jumlah slot palet dalam kondisi usulan sebanyak 492 slot palet berada diantara maksimum inventory dan minimum inventory dengan jumlah slot palet untuk masingmasing adalah 731 dan 418 secara berturut-turut maka hasil jumlah slot palet kondisi usulan telah valid. Jika dalam suatu bulan tertentu jumlah inventory yang berada di gudang melebihi batas yang dapat ditampung dalam kondisi usulan tersebut, maka solusi yang paling baik untuk adalah dengan menyewa temporary storage. Jika perusahaan melakukan penambahan rak maka akan merugikan dari sisi utilisasi dan investasi.

\section{KESIMPULAN}

Meningkatnya kapasitas dari gudang dengan kondisi awal yang hanya dapat menampung 156 slot palet menjadi 492 slot palet pada kondisi usulan. Dengan komposisi sebagai berikut: 
- Rak drive-in : 39 lane dengan kedalaman $\mathrm{r}=3$ (1 lane $=12$ slot palet) dengan total 468 slot palet.

- Rak selective : 6 lane (1 lane $=4$ slot palet $)$ dengna total 24 slot palet.

Selain itu, meningkatnya persentase utilisasi dari $18 \%$ pada kondisi saat ini menjadi 57\% pada kondisi usulan.

\section{DAFTAR PUSTAKA}

[1] Patel, J. (2011). A Study of Working Capital Management in Cement Industry in India. $\mathrm{PhD}$ thesis, Saurashtra University.

[2] Prayoga, A., Damayanti, D., Astuti, M. (2014). Usulan Perbaikan Alokasi Penyimpanan Barang dengan Metode Class Based Storage pada Gudang Bahan Baku 1 PT SMA. Jurnal Rekayasa Sistem dan Industri Volume 1, Nomor 2, Oktober 2014.

[3] Tompkins, J. (2010). Facilities Planning. USA: John Wiley \& Sons, Inc

[4] Petrovic D., Roy R., Petrovic R. (1999). Supply chain modeling using fuzzy sets. International Journal of Production Economics 59, Elsevier Science, pp. 443-453.
[5] Richard, G. (2014). Warehouse Management : A Complete Guide To Improving Efficiency. United States: Kogan Page Limited.

[6] Frazelle, E. (2002). World-Class Warehousing and Material Handling. Singapore: McGraw-Hill.

[7] Sriwana, I., Yulianto., Ashari, R. (2013). Pengelolaan Tata Letak Material di Gudang Kolong Hitam untuk Meningkatkan Utilitas Gudang (Studi Kasus di PT Sawindo Kencana, Tempilang, Bangka). Jurnal Inovisi Vol. 9, No. 2, Oktober 2013.

[8] Ferrara, A., Gebennini, E., Grassi, A., \& Rimini, B. (2014). An Optimization Model for The Design of Rack Storage Systems. Proceeding of IIE Annual Conference and Expo 2014, At Montreal, Canada

[9] Nofal, R., Yanuar, A., \& Santosa, B. (2016). 2. Design of Chemical Products Warehouse Layout Using Heuristic Approach and Share Storage Method to Improve Capacity and Reduce Out Of Block Products. Proceeding of the 11th International Conference of Logistics and Supply Chain Systems (ICLS,) 2016.

[10] Hassan, M.M.D. (2002), A framework for the design of warehouse layout, Journal Facilities, Vol. 20 Nos 13/14, pp. $432-40$
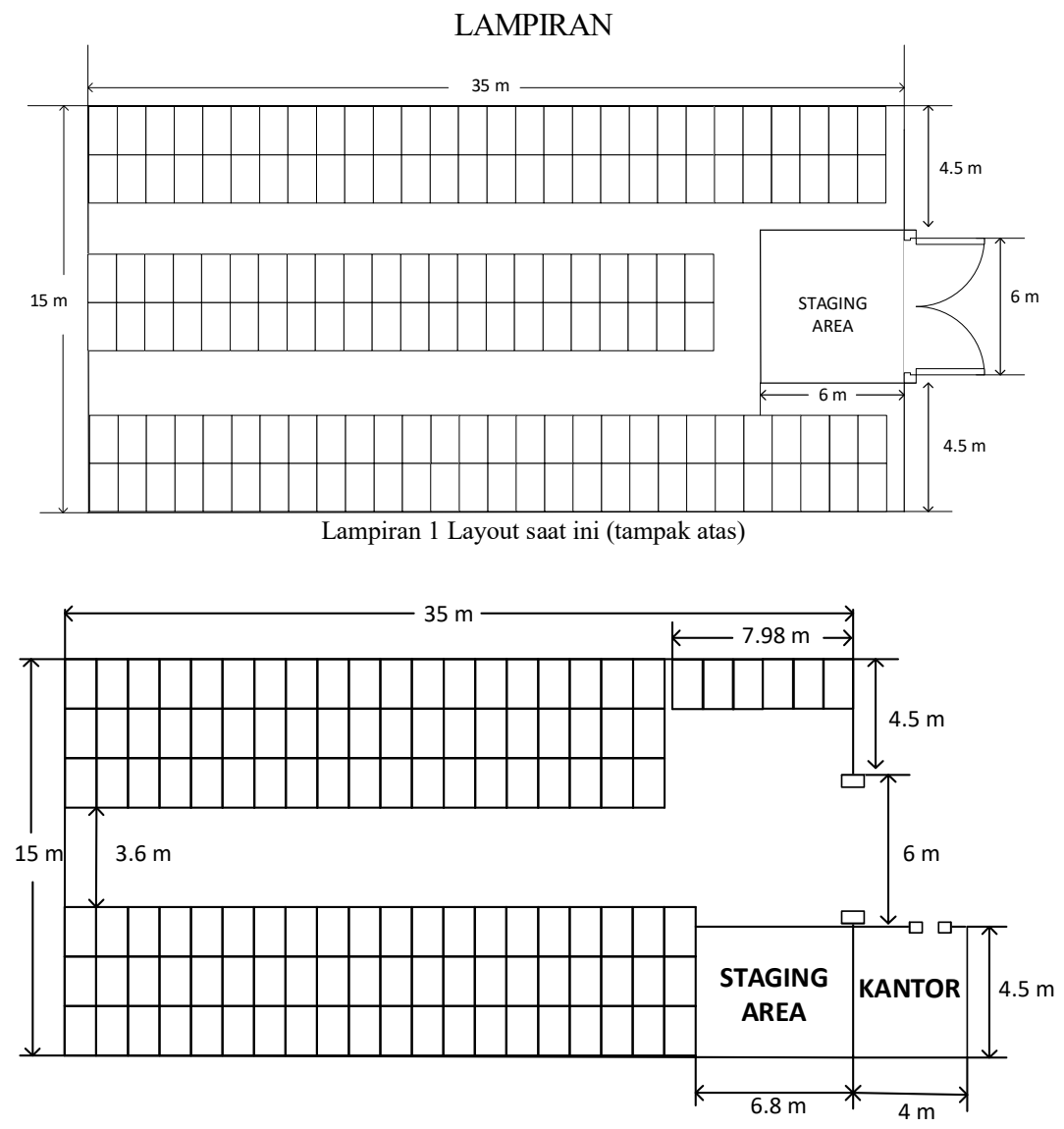

Lampiran 2 Layout usulan (tampak atas) 